УДК 33

DOI $10.21661 / \mathrm{r}-463273$

\title{
К.К. Мартынов
}

\section{ЭЛЕКТРОЭНЕРГЕТИЧЕСКИЙ РЫНОК ШВЕЦИИ: ПОЛИТИКА ЦЕНООБРАЗОВАНИЯ И ЭКОНОМИЧЕСКОЕ РЕГУЛИРОВАНИЕ}

Аннотация: в статье рассмотрена трансформация рынка электроэнергии Швеции начиная с 2000-х г2. Обозначены основные принципы образования цен и механизмы экономического регулирования, используемые в стране. Представлены основные проблемы на электроэнергетическом рынке Швеции на современном этапе.

Ключевые слова: энергетические рынки, энергоносители, ценообразование, экономическое регулирование, Швеция.

\section{K.K. Martynov \\ ELECTRICITY MARKET OF SWEDEN: PRICING POLICY AND ECONOMIC REGULATION}

Abstract: the subject of the article covers the transformation of the electricity market in Sweden starting from the 2000s. The author indicates the basic principles of pricing and economic regulation mechanisms used in the country. Main problems in the electric power market of Sweden at the present stage are also considered.

Keywords: energy markets, energy resources, pricing, economic regulation, Sweden.

Предпосылкой безопасного и эффективного энергоснабжения являются стабильно функционирующие энергетические рынки. Глобальные события создают потребность в рыночных механизмах и других мерах, которые могут предотвратить и смягчить последствия возможных кризисных явлений. Для того чтобы эти механизмы работали, существует сотрудничество на международном, национальном, региональном и местном уровнях. 
В связи с этим реализация концепции экономики «без нефтяной зависимости» в Швеции на экономическом уровне, прежде всего, затронула энергетические рынки и цены на энергию. После проведенной еще в 1990-х годах либерализации рынка энергоносителей правительство Швеции рассматривает энергетические рынки с эффективной конкуренцией, потреблением ресурсов и ценообразованием в качестве фундаментальной основы для своей комплексной политики в области климата и энергетики. С момента принятия концепции Швеция осуществила ряд реформ на энергетическом рынке, затрагивающие важные аспекты защиты потребителей, полномочия и задачи регулирующих органов, а также регламент поставки электроэнергии и газа.

Крайне важным для шведской экономики является поддержание баланса между поставками и потреблением электроэнергии в энергетической системе. Поэтому в 2002 году Швеция объединила свою электроэнергетическую систему с системами соседних стран Северной Европы. Наличие общей платформы позволяет этим странам импортировать или экспортировать электроэнергию в зависимости от того, где возникает ее дефицит.

В связи с этим шведскую электроэнергетическую систему следует рассматривать как часть регионального электроэнергетического рынка Северной Европы, в состав которого входят Дания, Финляндия, Норвегия, а также страны Прибалтики. Практически вся электроэнергия, производимая в Швеции, продается, и около 94\% национального потребления электроэнергии покупается через «Nord Pool Spot» на конкурентной основе. Биржа «Nord Pool Spot», таким образом, выступает в качестве основного инструмента торговли электроэнергией для Швеции, как и для других североевропейских стран. Биржа является основным инструментом ценообразования на электроэнергию в Швеции. Спотовые цены «Nord Pool Spot» (цены на поставку электроэнергии на следующий день) используются в качестве расчетных как при поставках промышленным потребителям, так и в расчетах с индивидуальными потребителями. 
Меры по поддержанию безопасного электроэнергетического баланса были приняты Швецией, в том числе, и на национальном уровне. Например, изменения в «Законе об электроэнергетике» [2] от 2005 года предусматривают введение более жестких требований к поставщикам и дистрибьюторам электроэнергии. Покупатели электроэнергии теперь имеют право на компенсацию за отключения электроэнергии, длящиеся более двенадцати часов. В 2011 году в тот же закон введена поправка, устанавливающая, что незапланированные перерывы в передаче электроэнергии не могут превышать 24 часа, если это не обусловлено причинами, выходящими за рамки контроля компаний электросетей. Помимо всего прочего, это функциональное требование способствовало увеличению числа электросетевых компаний, осуществляющих комплексные меры по защите от атмосферных воздействий.

Особую роль в повышении энергоэффективности данного сектора играет система сертификации электроэнергии или система «зеленых сертификатов». Она представляет собой рыночную систему поддержки, целью которой является увеличение доли производства возобновляемой электроэнергии. За каждый МВтч электроэнергии, произведенной из возобновляемых источников энергии, производитель получает сертификат электроэнергии, который затем получает рыночную стоимость перепродажи. Зачастую компании имеют квотированные объемы производства для покупки сертификатов. То есть, поставщики электроэнергии вынуждены покупать определенную долю сертификатов в соотношении с объемом продаж или потребления электроэнергии. Доля устанавливается через процентную ставку (квоту) за каждый год. Квоты рассчитываются на основе ожидаемого расширения возобновляемой электроэнергии, ожидаемой продажи электроэнергии и использования электроэнергии организациями, имеющими квотные обязательства.

С 1 января 2012 года Швеция и Норвегия имеют общий рынок сертификатов электроэнергии в рамках двухстороннего соглашения между странами от 29 июня 2011 года [1] Оно предусматривает создание общего рынка сертификатов электроэнергии на период 2012-2036 гг. При этом каждая страна имеет свое 
национальное законодательство, регулирующее системы сертификатов, которые также могут продаваться через границу на совместном рынке. Производитель электроэнергии может получить сертификат независимо от того, производится ли электричество в Норвегии или в Швеции, а сертификаты обеих стран могут использоваться по обе стороны границы. Объединение рынков преследует цель увеличения производства возобновляемой электроэнергии в установленный период времени. Ожидается, что общий, более крупный рынок, вероятно, улучшит функционирование с обеих сторон, обеспечит более стабильные цены сертификатов и экономическую эффективность внедрения возобновляемых источников энергии.

Швеция также добилась значительного прогресса в реформировании рынка электроэнергии. Основная цель, преследуемая правительством, - поддержание высокого уровня конкуренции, наличие большого выбора поставщика для потребителя и создание условий эффективного ценообразования за счет открытой и развитой торговли электроэнергией.

Начиная еще с 1990-х годов, Шведский рынок электроэнергии является полностью либерализированым - клиенты могут свободно выбирать своего поставщика. Деятельность по передаче и распределению электроэнергии разделяется посредством разделения собственности, в то время как большинство активов распределительных сетей остаются в собственности государства и являются регулируемой монополией.

В 2011 году на элетроэнергетическом рынке Швеции была принята значимая для ценообразования реформа. В результате работы Европейской комиссии страна была поделена на четыре региона электроснабжения, что изменило прежний метод управления ограничениями передачи в шведской электросети. Подобное секторальное разделение укрепляет и расширяет национальную сеть, а также дает четкое представление о том, где в стране существует потребность в увеличении производства электроэнергии, чтобы лучше соответствовать уровню потребления в конкретном регионе. Также в связи с этим разделением в Швеции 
нет фиксированной цены на электроэнергию. Цена электроэнергии может отличаться в зависимости от региона электроснабжения и ограничений, существующих между ними.

При этом структура цены на электроэнергию сохраняется общей для всей территории Швеции. По состоянию на 1 января 2014 года цена на электроэнергию для конечного потребителя в Швеции, состоит из цены самой электрической энергии - 46\%, «зеленых сертификатов» - 3\%, цены за использование сетей $15 \%$, налогов (энергетического налога и НДС) - 36\% [4]. Потребитель может повлиять на себестоимость электроэнергии и сертификатов путем выбора поставщика или пересмотра договора.

Поскольку электроэнергия рассматривается как одна из альтернатив замены ископаемых видов топлива в Швеции, розничные цены на электроэнергию в последние годы увеличиваются. За период 2004-2014 гг. цены на электроэнергию для квартир, отдельных дома без/с электрообогревом, сельскохозяйственных и лесопромышленных объектов, малых предприятий и бизнеса возросли более чем на 40\%. Общая стоимость электроэнергии для домохозяйств в 2014 году составила 1,37 SEK за кВтч или 27400 SEK (3 200 евро) за год [3].

Сегодня это превращается в определенного рода проблему для шведского потребителя, наряду с ограниченностью фактического выбора поставщика электроэнергии. Примерно 80\% объемов производства и распределения электроэнергии в Швеции контролируется тремя крупнейшими компаниями - «Vattenfall», «Fortum» и «E.ON». Доля этих компаний в розничных продажах электроэнергии несколько ниже, но тем менее, их доминирование достаточно явно. Учитывая также, что не во всех регионах страны представлены все три эти компании, зачастую у потребителей просто нет выбора. Вместе с этим функционирование рынка электроэнергии в Швеции в последние годы вызывает резкую критику потребителей энергии, в особенности в жилом секторе, представленном, главным образом, отдельными домами с электрообогревом. Основной повод для критики - высокие цены на электроэнергию. 
Тем не менее, с начала дерегулирования в 1996 году и создание общего рынка электроэнергии Северных стран, шведская электроэнергетическая система рассматривается как образец для подражания для либерализации рынка и региональной интеграции.

\section{Список литературы}

1. Agreement between the Government of the Kingdom of Norway and the Government of the Kingdom of Sweden on a common market for Electricity Certificates. 29th of June 2011 [Электронный ресурс]. - Режим доступа: https://www.regjeringen.no/globalassets/upload/oed/pdf_filer_2/elsertifikater/agreement_on_a_common_market_for_electricity_certificates.pdf

2. Electricity Act (1997:857) Sweden [Электронный pecypc]. - Режим доступа: http://ei.se/Documents/Publikationer/lagar_pa_engelska/Electricity_Act_.pdf

3. Energy Efficiency trends and policies in Sweden. Swedish Energy Agency. 2015 [Электронный pecypc]. - Режим доступа: http://www.odyssee-mure.eu/publications/national-reports/energy-efficiency-sweden.pdf

4. Energy Policies of IEA Countries 2013 Review, Sweden. International Energy Agency. - France, 2013 [Электронный pecypc]. - Режим доступа: https://www.iea.org/publications/freepublications/publication/Sweden2013_free.pdf

Мартынов Кирилл Константинович - студент ФГАОУ ВО «Северный (Арктический) федеральный университет им. М.В. Ломоносова», Россия, Архангельск.

Martynov Kirill Konstantinovich - student at FSAEI of HE "Northern (Arctic) Federal University named after M.V. Lomonosov", Russia, Arkhangelsk. 